Prepared for the U.S. Department of Energy

under Contract DE-AC05-76RL01830

\title{
Technical Review of the CENWP Computational Fluid Dynamics Model of the John Day Dam Forebay
}

\author{
CL Rakowski \\ MC Richmond
} JA Serkowski

JA Serkowski

2010

\section{Pacific Northwest}

NATIONAL LABORATORY

Proudly Operated by Battelle Since 1965 


\title{
DISCLAIMER
}

This report was prepared as an account of work sponsored by an agency of the United States Government. Neither the United States Government nor any agency thereof, nor Battelle Memorial Institute, nor any of their employees, makes any warranty, express or implied, or assumes any legal liability or responsibility for the accuracy, completeness, or usefulness of any information, apparatus, product, or process disclosed, or represents that its use would not infringe privately owned rights. Reference herein to any specific commercial product, process, or service by trade name, trademark, manufacturer, or otherwise does not necessarily constitute or imply its endorsement, recommendation, or favoring by the United States Government or any agency thereof, or Battelle Memorial Institute. The views and opinions of authors expressed herein do not necessarily state or reflect those of the United States Government or any agency thereof.

\author{
PACIFIC NORTHWEST NATIONAL LABORATORY \\ operated by \\ BATTELLE \\ for the \\ UNITED STATES DEPARTMENT OF ENERGY \\ under Contract DE-AC05-76RL01830
}

Printed in the United States of America
Available to DOE and DOE contractors from the Office of Scientific and Technical Information,
P.O. Box 62, Oak Ridge, TN 37831-0062;
ph: (865) 576-8401
fax: $(865) 576-5728$
email: reports@adonis.osti.gov

\footnotetext{
Available to the public from the National Technical Information Service, U.S. Department of Commerce, 5285 Port Royal Rd., Springfield, VA 22161 ph: (800) 553-6847 fax: $(703) 605-6900$ email: orders@ntis.fedworld.gov online ordering: http://www.ntis.gov/ordering.htm
}

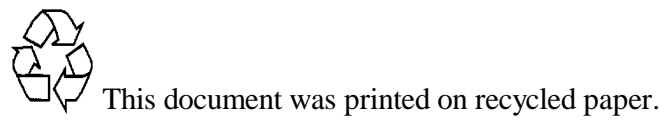




\title{
Technical Review of the CENWP Computational Fluid Dynamics Model of the John Day Dam Forebay
}

\author{
CL Rakowski MC Richmond
}

JA Serkowski

2010

Prepared for

US Army Corps of Engineers, Portland District

Portland, OR

Pacific Northwest National Laboratory

Richland, Washington 99352 



\section{Summary}

The US Army Corps of Engineers Portland District (CENWP) has developed a computational fluid dynamics (CFD) model of the John Day forebay on the Columbia River to aid in the development and design of alternatives to improve juvenile salmon passage at the John Day Project.

At the request of CENWP, Pacific Northwest National Laboratory (PNNL) Hydrology Group has conducted a technical review of CENWP's CFD model run in CFD solver software, STAR-CD. PNNL has extensive experience developing and applying 3D CFD models run in STAR-CD for Columbia River hydroelectric projects (see Rakowski et al. 2000, Johnson et al. 2005a, Rakowski et al.2006b a, 2008, Richmond et al. 2009, Rakowski et al. 2005).

The John Day forebay model developed by CENWP is adequately configured and validated. The model is to be used for simulating forebay hydraulics for structural and operational alternatives. The approach and methods are sound, however CENWP has identified some improvements that need to be made for future models and for modifications to this existing model. 



\section{Acknowledgments}

Financial support for this study was provided by the US Army Corps of Engineers under MIPR W66QKZ82596904. The authors would like to thank Sean Askelson and Laurie Ebner, US Army Corps of Engineers, Portland District, for the discussions, support, and insight that improved this study. The authors would like to thank Lyle Hibler (PNNL) for his careful technical review. His role in the preparation of this document were appreciated and improved the final product. 



\section{Abbreviations and Acronyms}

\begin{tabular}{|c|c|}
\hline ABBREV & DEFINITION \\
\hline $2 \mathrm{D}$ & two dimensional \\
\hline $3 \mathrm{D}$ & three dimensional \\
\hline $\mathrm{ADCP}$ & acoustic Doppler current profiler \\
\hline AMG & Algebraic Multi-Grid \\
\hline BGS & Behavior Guidance System \\
\hline CENWP & U.S. Army Corps of Engineers, Portland District \\
\hline CFD & computational fluid dynamics \\
\hline DGAS & Dissolved Gas Abatement Study \\
\hline ERDC & Engineer Research and Development Center, Vicksburg, MS \\
\hline FBE & Forebay elevation \\
\hline GIS & Geographic Information System \\
\hline JDA & John Day Dam \\
\hline $\mathrm{kcfs}$ & Thousand cubic feet per second \\
\hline MASS2 & Modular Aquatic Simulation System in Two Dimensions \\
\hline NAD27 & North American Datum of 1927 \\
\hline NAD83 & North American Datum of 1983 \\
\hline NGVD27/47 & National Geodetic Vertical Datum of 1929 with the 1947 adjustment \\
\hline ORN & Oregon North State Plane feet \\
\hline MARS & monotone advection and reconstruction scheme \\
\hline $\mathrm{PH}$ & Powerhouse \\
\hline PNNL & Pacific Northwest National Laboratory \\
\hline STL & stereolithography \\
\hline TIN & triangulated irregular network \\
\hline TSW & Temporary Spillway Weir \\
\hline USACE & U.S. Army Corps of Engineers \\
\hline USGS & U.S. Geological Survey \\
\hline VMag & Velocity magnitude \\
\hline UD & Upwind difference \\
\hline VOF & volume of fluid \\
\hline
\end{tabular}





\section{Contents}

Summary . . . . . . . . . . . . . . . . . . . . . iii

Acknowledgments .......................... . . . . . .

Abbreviations and Acronyms . . . . . . . . . . . . . . . . vii

1.0 Introduction $\ldots \ldots \ldots \ldots \ldots \ldots \ldots \ldots \ldots$

2.0 Model Development, Configuration, and Validation $\quad \ldots \ldots$. . . . . . . . . . . . . 2.1

2.1 Overall Modeling Requirements and Expected Applications . . . . . . . . . . . 2.1

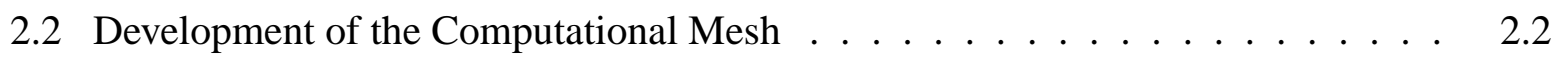

2.2 .1 Bathymetry . . . . . . . . . . . . . . . . 2.2

2.2 .2 Mesh Extent . . . . . . . . . . . . . . . . 2.3

$2.2 .3 \quad$ Far-field Computational Mesh . . . . . . . . . . . . . . . . 2.3

2.2 .4 Near-field Computational Mesh . . . . . . . . . . . . . . . 2.4

$2.2 .5 \quad$ Overall Computational Mesh $\ldots \ldots \ldots \ldots$

2.3 Model Configuration and Boundary Conditions . . . . . . . . . . . . . . . 2.5

2.3 .1 Boundary Locations and Configuration . . . . . . . . . . . . 2.6

2.4 Model Validation and Grid Refinement $\ldots \ldots$. . . . . . . . . . . . . . 2.6

3.0 Results and Discussion . . . . . . . . . . . . . . . . . . . . . . 3.1

3.1 General Observations $\ldots \ldots \ldots \ldots . \ldots \ldots$

3.2 Model Validation . . . . . . . . . . . . . . . . . . . 3.1

$3.2 .1 \quad$ Differencing Scheme $\ldots \ldots \ldots \ldots . \ldots \ldots$

3.2 .2 Model Refinement $\ldots \ldots \ldots \ldots$

4.0 Conclusions and Recommendations $\quad \ldots \ldots$. . . . . . . . . . . . . . . . 4.1

5.0 References . . . . . . . . . . . . . . . . . . . . 5.1 


\section{Figures}

3.1 Comparison of Vectors from ADCP Measured Velocity, CENWP MARS Modeled Velocity, and the CENWP UD Model at an Elevation of $254 \mathrm{ft}$ and $244 \mathrm{ft}]$. . . . . . 3.3

3.2 Comparison of Vectors from ADCP Measured Velocity, CENWP MARS Modeled Velocity, and the CENWP UD Model at an Elevation of $234 \mathrm{ft}$ and $224 \mathrm{ft}]$. . . . . . 3.4

3.3 Comparison of Vectors from ADCP Measured Velocity, CENWP MARS Modeled Velocity, and the CENWP UD Model at an Elevation of $214 \mathrm{ft}$ and $204 \mathrm{ft}$. . . . . . 3.5

3.4 Comparison of Vectors from ADCP Measured Velocity, CENWP MARS modeled Velocity, and the CENWP UD Model at an Elevation of $164 \mathrm{ft}$. . . . . . . . . . . . 3.6

3.5 One to One Comparison of ADCP-measured and CENWP Modeled Velocity Mag-

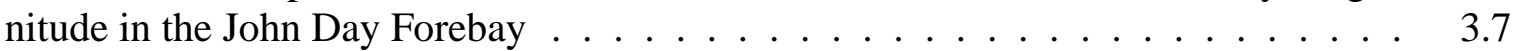

3.6 Comparison of Vectors from ADCP Measured Velocity, CENWP Modeled Velocity, and the CENWP Model as Refined by PNNL at an Elevation of $254 \mathrm{ft}$ and 244

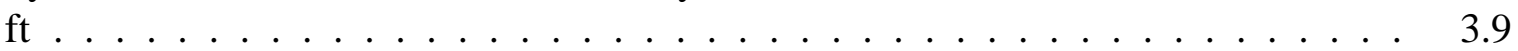

3.7 Comparison of Vectors from ADCP Measured Velocity, CENWP Modeled Velocity, and the CENWP Model as Refined by PNNL at an Elevation of $234 \mathrm{ft}$ and 224

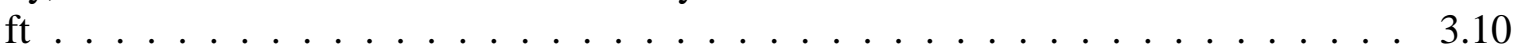

3.8 Comparison of Vectors from ADCP Measured Velocity, CENWP Modeled Velocity, and the CENWP Model as Refined by PNNL at an Elevation of $214 \mathrm{ft}$ and 204

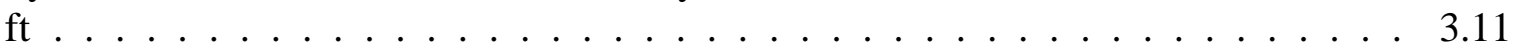

3.9 Comparison of Vectors from ADCP Measured Velocity, CENWP Modeled Velocity, and the CENWP Model as Refined by PNNL at an Elevation of $164 \mathrm{ft}$. . . . . 3.12 


\subsection{Introduction}

The US Army Corps of Engineers Portland District (CENWP) has developed a computational fluid dynamics (CFD) model of the John Day forebay on the Columbia River to aid in the development and design of alternatives to improve juvenile salmon passage at the John Day Project. To date, a reduced-scale physical model (located at ERDC in Vicksburg, MS) has been used to develop alternatives and demonstrate their impact on flow conditions to regional fisheries representatives. However, there are limitations to the physical model that make it desirable to develop additional hydraulic tools to use in evaluating concepts and designs. CFD has become a commonly used tool in hydraulic engineering; Columbia River examples include Politano et al. (2009), ENSR (2001), and Weber et al. (2005).

At the request of CENWP, Pacific Northwest National Laboratory (PNNL) Hydrology Group has conducted a technical review of CENWP's CFD model run in CFD solver software, STAR-CD. PNNL has extensive experience developing and applying 3D CFD models run in STAR-CD for Columbia River hydroelectric projects (see Rakowski et al. 2000, Johnson et al. 2005a, Rakowski et al.2006b, a, 2008, Richmond et al.2009, Rakowski et al. 2005).

This document provides a technical review of the CFD model developed by USACE personnel for the John Day forebay. The review consists of evaluating the computational mesh and model configuration, validation, and application. 



\subsection{Model Development, Configuration, and Validation}

The STAR-CD model for the John Day forebay was obtained from CENWP in February 2009. This report does not reflect any updates or changes made to the model since that date. Askelson (2009) describes the the CENWP model development and validation.

A summary of best practices for CFD for marine applications was compiled by WS Atkins Consultants and NSC 2002 Standard best practices include:

- Clearly define the study objects and modeling requirements,

- Define the area of primary interest,

- Determine the level of validation necessary,

- Evaluate the model parameters used for boundary conditions, the boundary location, and the geometry specification,

- Assess model convergence and error and that reasonable flows are modeled, and

- Conduct grid convergence studies and solution sensitivity tests.

These best practices, and the details that fall under each above category, will be used as a framework in the discussion of the CENWP John Day forebay model.

\subsection{Overall Modeling Requirements and Expected Applications}

The John Day forebay CFD model was to be used to evaluate near-project forebay alternatives, both structural and operational. Structural alternatives include the use of temporary spillway weirs (TSWs) and the addition of a behavioral guidance system (BGS) to the forebay. The TSWs potentially provide surface flows to attract juvenile fish and possibly better tailrace egress past the dam than existing spillway or powerhouse routes of passage. The BGS has potential to guide juvenile fish away from the powerhouse and toward the spillway where overall survival may be increased.

Operational alternatives included:

- changes to spill patterns (how the spill flow is distributed between bays),

- vertical spill location (below the tainter gates or at the top of the water column for TSWs),

- spill requirements based on construction of tailrace structures (such as a spillwall between bays 12 and 13),

- the flow split between the powerhouse and spillway for any of the patterns, and 
- total river flow.

Thus, a steady-state rigid lid CFD model is appropriate for modeling these alternatives.

\subsection{Development of the Computational Mesh}

STAR-CD (CD-adapco, Computational Dynamics Limited 2006) version 4.06 was the CFD flow solver used to simulate forebay flow pattern. STAR-CD has been used successfully for past forebay and tailrace studies on the Columbia River (for example, see Rakowski et al. 2000, 2006b, 2005). Past computational meshes created by PNNL allow for alternative operational and structural scenarios to be run. CENWP personnel have often used these models to run additional flow alternatives. This model (the computational mesh) was created by CENWP personnel using the software tools (e.g., Microstation, STAR-CCM+ (CD-adapco, Computational Dynamics Limited 2008), and STAR-CD) available to them. Multiple tools are required to create a computational mesh. A bathymetric surface of the river must be created from river point surveys and contoured data, and a CAD developed for the engineered structures. These data were used to created the computational mesh for the forebay. The resulting computational mesh was used in a CFD flow solver.

The underlying data describing the computational domains are very different (the river vs. engineered structures) and thus require that the computational domain be built in pieces and assembled. As this model was built with the intention of adding structures near the dam, it was forward thinking to create a model with a section that would be easily replaced with a remeshed section that included various proposed structures. In this section, the overall approach to model creation and assembly will be discussed.

\subsubsection{Bathymetry}

The bathymetric surface was created from river survey data. These data were collected in sections of the river with depths greater than $5 \mathrm{ft}$. In Askelson (2009), the description of the bathymetry does not note the datum and accuracy of the survey point measurements. It is also not noted if control points were used in the joining of the dam structure to river bathymetry. We recommend adding this information as a standard practice. For this work, Tecplot ${ }^{T M}$ was used to create an triangulated irregular network (TIN) mesh and to smooth that mesh. Although this approach creates a single-valued bathymetric surface, there tend to be artifacts of the contouring process such as scalloping near the shore and areas of higher gradients of elevation resulting from the spacing of the cross-section bathymetry measurements.

In Askelson (2009), there is discussion of improvement of these artifacts in future work by the use of an offset regular mesh for the TIN of the bathymetry points. Although this will give a better mesh, it doesn't address the underlying issue of bathymetry processing artifacts.

At PNNL, we have found superior results using Surfer ${ }^{T M}$ (Golden Software). Surfer allows the anisotropic weighting of data; this features allows us to take advantage of the typically streamwise smoothed nature of bathymetric data. Thus the scalloping along the shorelines and "stripes" of the sampling transects across the river can be reduced. Another option is to 
manually add contours or points in high gradient areas.

It is noted in the report that all newer models will be built in the Oregon North coordinate system. It should be noted that it would be highly desirable to create the model in a geo-referenced coordinate system, however, it has been necessary to translate STAR-CD models by an offset to reduce the number of significant digits for spatial coordinates. STAR-CD documentation specifies that vertex coordinates should not be greater than $10^{5}$.

\subsubsection{Mesh Extent}

The computational mesh extends about $3400 \mathrm{~m}$ upstream from the project, $1240 \mathrm{~m}$ wide. It is separated into a far-field, mid-field and near-project sections. The far field extends from the upstream boundary to about $1200 \mathrm{~m}$ from the project. The mid-field extends from $1220 \mathrm{~m}$ to $575 \mathrm{~m}$ from the project in front of the powerhouse, and about $220 \mathrm{~m}$ from the spillway. The near-project is the area upstream of the spillway and powerhouse. These areas were meshed separately and joined to the far- and mid-field meshes. Two different tools and approaches were used to create the computational meshes. As is shown in the validation section, the location of the upstream boundary is sufficiently upstream to allow the flow field to be a product of channel geometry rather than boundary location.

\subsubsection{Far-field Computational Mesh}

The mesh for the river was created in STAR-CD v4.06. The approach was similar to past PNNL work in that a single-valued surface was "swept up" to a water-surface elevation to create the volume mesh. The single-valued surface was created using a series of $2 \mathrm{D}$ triangles (shell cells); the shell corners were then projected to the bathymetric surface described in Section 2.2.1. The shallow areas of this bathymetric surface were treated separately to reduce the aspect ratios of these cells that were typically located near the shores. The method used to create the forebay triangles create all the triangles to be, in plan view, of equal area. It is desirable to have shell cells of a smaller area in the shallow zones thus allowing for better resolution of the topography and reducing aspect ratios while maintain a sufficient number of cells in the vertical. Best practices are to maintain aspect ratios less than 20, STAR-CD recommends less than 10.

In the far-field forebay, the bathymetry was based on rectangular shell cells split into a right triangle cells that have a plan-view dimension of about $30.5 \mathrm{~m}$ and $23 \mathrm{~m}$ for the sides joined by the right angle of the triangle. In the mid-field, the triangles sides adjoining the right angle were about $13 \mathrm{~m}$ by $15.25 \mathrm{~m}$. These plan-view triangles were then projected onto the bathymetric surface. Triangles with elevations above the water surface elevation were removed from the model and a minimum depth was used on the remaining triangles. These remaining triangles were segregated into shallow and not-shallow faces for the purpose of volume mesh creation. The shallow cells had 8 cells created in the vertical between the bathymetric shell and the water surface elevation in evenly spaced increments. The deeper shells had 16 vertical cells. These manipulations have two impacts that probably have little effect on the overall simulation results: Some shallow areas are deeper than the prototype, but it also limited the aspect ratio of the shallow cells when the volume mesh was created. The higher aspect ratio cells were split with a 2 by 2 by 1 (in the $\mathrm{x}, \mathrm{y}$, and $\mathrm{z}$ directions, respectively) refinement to cut the aspect ratio in half. 


\subsubsection{Near-field Computational Mesh}

This part of the mesh was created in STAR-CCM+ ${ }^{T M}$ version 3. In this tool, some control over mesh quality was lost and was not as easily controlled in the version of STAR-CCM+ used. Newer versions of the STAR-CCM+ code have better anisotropic controls to allow increased vertical resolution and thus better vertical resolution will be possible in future models. The mesh included engineered structures (turbine intakes and spillway gates) and the surveyed bathymetry in front of the project.

We noted some odd features to the near-field computational mesh. The mesh was more refined at the far-field / near-field interface than it was on either side of the interface. At the interface, there were about 15 vertical layers in the near-field mesh, 16 in the far-field mesh. This coarser section extended to about $24 \mathrm{~m}$ from the powerhouse, and then the mesh transitioned to 16 layers. Within $19 \mathrm{~m}$ of the powerhouse, it transitioned to 32 layers, then to 64 by the intakes. However, in the near-field interior, the mesh transitioned to only eight layers in the vertical in front of the powerhouse, six in front of the spillway. It seems that in this area of interest, that maintaining the vertical resolution would be desired to discern the near-field impacts to flow. Anisotropic mesh generation should be implemented to allow the larger lateral extent of the cells, but, at a minimum, maintain the far-field vertical resolution. There were additional issues with some of the cell shapes at the pier noses and near the turbine intakes. The meshing at the spillway did not have as many issues as there was a good transition from very resolved on the tainter gate $(0.2 \mathrm{~m}$ cells edges) although the mesh needed more vertical resolution 25 to $50 \mathrm{~m}$ from the tainter gate.

There were a few concave cells in the model that are an artifact of the STAR-CCM+ meshing software. At the point in time this model was created, there was no simple way of fixing them although newer code versions have better mesh quality control. However, it does point out the need to implement cell quality checks and and cell quality remediation in the flow solver. Implementing these (discussed below) changes how the STAR-CD solver handles these cells and makes the solver more robust.

The stop log structure were included for the computational mesh of the spillway gates; however, there was not a sufficient number of cells in the slots for them to accurately model flow. Theoretically, the cells in the gate well slots could be refined for future models when flow solutions in these areas are important. It should be noted that polyhedral cells can not be simply refined. Polyhedral cells can be either a many-faced volume, or more like a brick (hexahedral cell) with one or more of the sides defined by multiple faces in the side plane. In polyhedral cells that are functionally hexahedral cells with a multiple faces on a side, it is possible to refine those cells in STAR-CD but requires a more involved process. It is not possible to refine the other non-hexahedral-like polyhedral cells.

\subsubsection{Overall Computational Mesh}

The computational mesh was created in components as described above, then assembled into a continuous mesh in STAR-CD. The model includes the powerhouse, spillway tainter gates, and the forebay bathymetry for about $3400 \mathrm{~m}$ upstream of the project. It includes the area of interest (near the project) and sufficient upstream extent so that the upstream boundary location doesn't 
impact the modeled flows near the area of interest.

The CFD model was built using meters (rather than feet) and the project and river bathymetry was oriented to the construction baseline. Although not crucial, past experience at PNNL has indicated it is a better choice to build the model in a geo-referenced coordinate system that can be more easily integrated into, and compared to, field-measured data. It is much easier to do a simple coordinate shift rather than a shift and rotation of the model results and geometry. In addition, it improves the ability to overlay results on orthophotos; these overlays provide additional context for the numerical results and often more intuitive understanding of results and the biological data collected at the dam.

The model is composed of 3 million fluid cells. These cells are prisms, hexahedral cells and polyhedral cells. An aspect ratio of 10 was exceeded in 277,513 cells, 53,746 exceeded an aspect ratio of 20. The higher aspect ratio cells are near the shorelines and the most upstream section of mesh. Near the project, there are a very limited number of high aspect ratio cells (19). Best practices suggest that cell aspect ratio should not exceed 20. Overall,however, the mesh quality should not adversely impact the quality of the numerical solution, especially near the project.

\subsection{Model Configuration and Boundary Conditions}

The overall configuration was very similar to other forebay applications on the Columbia River(e.g., Rakowski et al.2000, Johnson et al.2005b, Rakowski et al.2006b). The STAR$\mathrm{CD}$ model was configured to run as a steady state model. A k- $\varepsilon$ high-Reynolds number turbulence closure with a standard wall function was used. The Algebraic Multi-Grid (AMG) solver for pressure was implemented, as recommended by CD-adapco. Best practices indicated that a second-order differencing scheme such as the Monotone Advection and Reconstruction Scheme (MARS) differencing scheme should be used. CD-adapco recommends using MARS for momentum, but using upwind differencing (UD) for turbulence qualities. However, a large number of iterations are required to achieve model convergence with MARS. Other modeling by PNNL has found that the more dissipative upwind differencing for momentum matches the field-measured velocities well. The model run in double precision. Relaxation coefficients of $0.4,0.18$, and 0.4 were used for momentum, pressure, and turbulence, respectively. Convergence residual tolerance was set at $10^{-4}$.

Missing from the model set up was a feature for improved handling of poor quality cells in the mesh (STAR-CD version 4.02 - 4.06). The code:

BEGIN CELLQUALITY

$\circ$

POST_QUALITY

END CELLQUALITY

should be added to the extended data in STAR-CD v4.02 and v4.06. A check box for this feature is in v4.08 and higher. This solver function handles the poor-quality cells in the mesh differently which makes the flow solution more robust. 


\subsubsection{Boundary Locations and Configuration}

This model was designed to answer questions near the dam. As such, the upstream boundary was sufficiently far from the area of interest for the boundary location to not influence results. This was demonstrated by the match to the field-measured velocity data mid-model and near the project. The upstream boundary was specified as a pressure boundary with specified turbulence intensity and length (10\% and $0.02 \mathrm{~m}$, respectively). These are values recommended by CD-adapco. Each location where flow leaves the model (turbine intakes and spillway gate locations) had a specified velocity (and turbulence quantities) that was orthogonal to the boundary. Outflow locations for which there was no flow were specified as walls. The water surface was specified as a slip wall.

\subsection{Model Validation and Grid Refinement}

The numerical model was run for conditions corresponding to the average conditions on the day Mannheim and Sweeney (2003) made high-quality ADCP velocity measurements in the John Day forebay. In addition, a mesh refinement case was run by PNNL.

The mesh refinement was done in STAR-CD. Cells were refined $2 \times 2 \times 1$ to improve the aspect ratio in the forebay, and refined (where possible) 2 by 2 by 2 (in the $\mathrm{x}, \mathrm{y}$, and $\mathrm{z}$ direction, respectively) in the portion of the mesh created in STAR-CCM+. This was accomplished using the csimplify and crefine commands in pro-STAR. The refined mesh had 23.8 million cells.

The results from these simulations were compared to the field-measured velocity data. These field-measured velocities were collected over a 10-minute period at each location. Data from outside a 10-ft radius of the desired boat position were excluded (Mannheim and Sweeney|2003).

Although more rigorous model validation typically includes field-measured velocity data at the high and low end of the discharge ranges to be modeled, these data were not available at the John Day Project, nor typically for other Columbia River Projects. Measurements were made for only one set of dam operations; those operations had no spillway flows. Consequently, we could not test the flow patterns for more complex flow splits. 


\subsection{Results and Discussion}

\subsection{General Observations}

The John Day forebay CFD model was designed to work in the relatively low-velocity forebay of the John Day Dam. Expected applications will typically use flow fields near the project face (e.g., for the comparison of flow nets resulting from different project operations or the use of the simulation results to provide a characterization of the physical environment for fish biological data) or just upstream of the project (e.g., assessing the potential impact of a BGS on the forebay flow). The approximations made for these runs - steady state with a flat, slip-wall lid and no wind - are appropriate for most applications. Caution should be used, however, when using this model to assess flow fields near a TSW or when compared to field data collected on windy days. If the details of flow hydraulics were needed in the drawdown area of a TSW, a free-surface model should be used.

The model settings, parameters, and levels of convergence discussed in 2.3 are similar to those used by PNNL for other applications on the Columbia River. For the most part, these conform to best practices or recommendations by the software vendor, CD-adapco.

One parameter often not checked in these forebay models is the $y+$ value. For the wall functions used, the $y+$ should be, in theory, between 1 and 100. In this and other forebay models, the $y+$ is much larger (1000s). However, in our experience, this does not adversely impact match to the field-measured validation data and decreases the size of the computational mesh.

For future work with BGS additions to the forebay, careful attention will be needed in terms of vertical resolution approaching the BGS and between the BGS and the project. In general, additional vertical refinement will be needed as well as added resolution near a BGS structure.

\subsection{Model Validation}

The impacts of differencing scheme and model refinement were considered. Additional turbulence closures were not tested, rather all runs were with the standard k- $\varepsilon$ high-Reynolds number.

\subsubsection{Differencing Scheme}

The model was run with the second-order MARS differencing scheme for momentum (a best practice) and with the first-order upwind differencing for comparison.

Figures 3.1 to 3.4 show the velocity vectors at the ADCP measurement points for the measured velocities, the CENWP model with MARS, and the CENWP model with UD. These are ordered from the near water surface (Figure 3.1), then down through the depths.

Note that the results for both differencing schemes were very similar for all ADCP points, the match to the measured data was worst at the most upstream (near the inflow boundary, especially in the upper bins) and just upstream of the dam face between the spillway and powerhouse. However, if one considers the large standard deviation for each measurement (shown in the black 
error bars in Figure 3.5 and often larger than the velocity magnitude), the measured to modeled velocities are acceptable for the river environment for both differencing schemes. These very large standard deviations indicate that the prototype flows measured were turbulent and transient. A steady-state numerical model will not capture these features. 

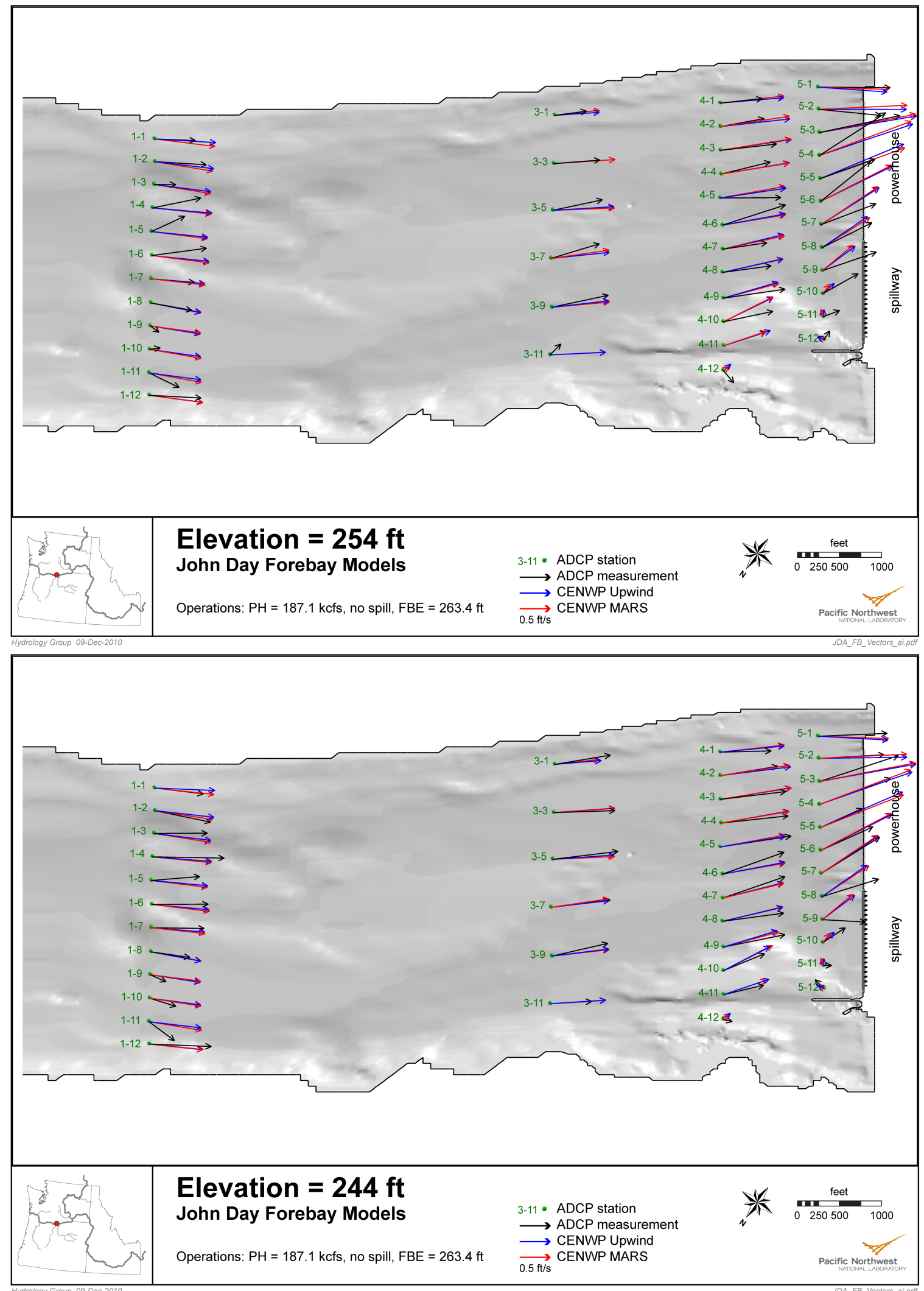

Figure 3.1. Comparison of Vectors from ADCP Measured Velocity, CENWP MARS Modeled Velocity, and the CENWP UD Model at an Elevation of $254 \mathrm{ft}$ (top) and $244 \mathrm{ft}$ (bottom) 

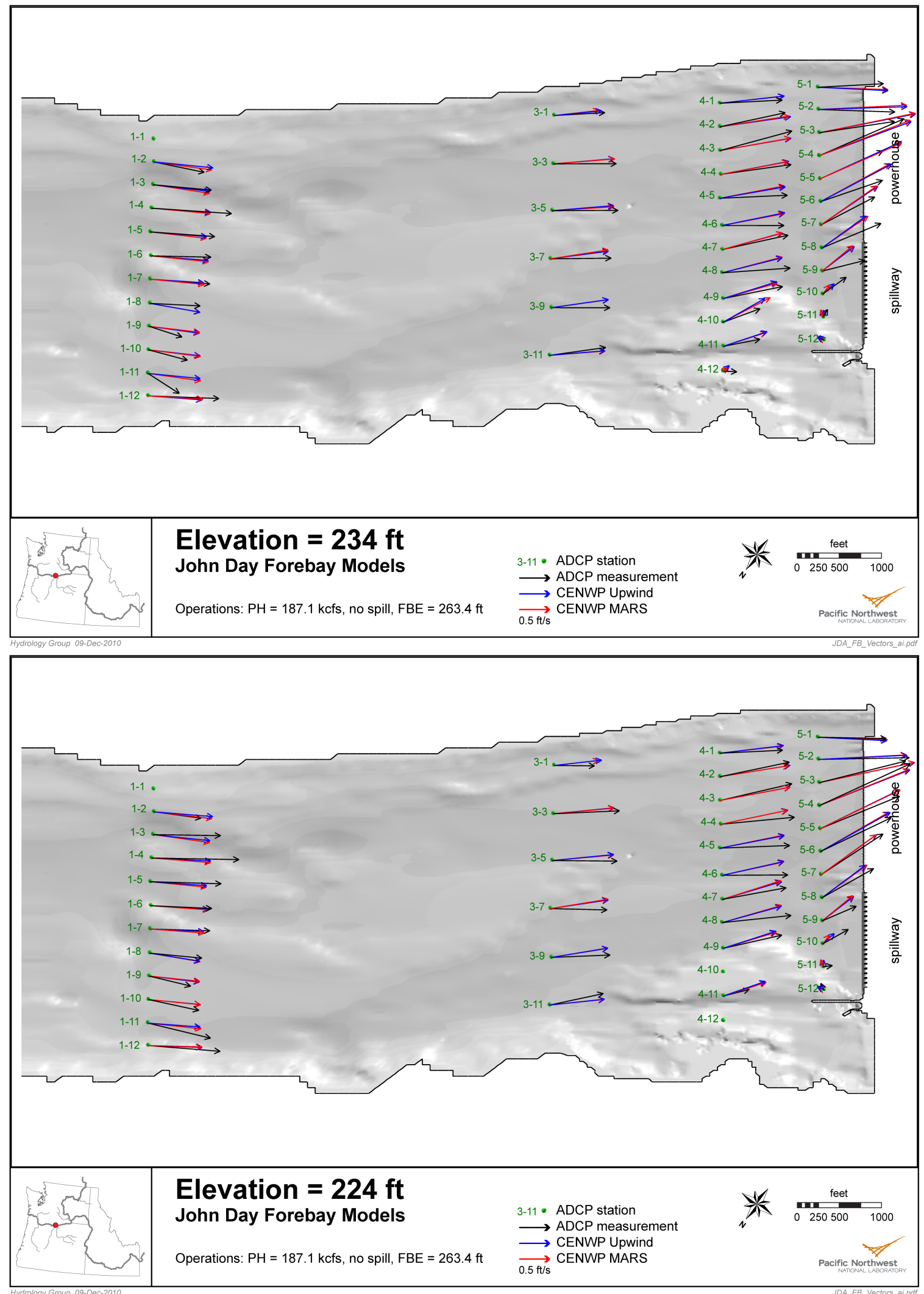

Figure 3.2. Comparison of Vectors from ADCP Measured Velocity, CENWP MARS Modeled Velocity, and the CENWP UD Model at an Elevation of $234 \mathrm{ft}$ (top) and $224 \mathrm{ft}$ (bottom) 

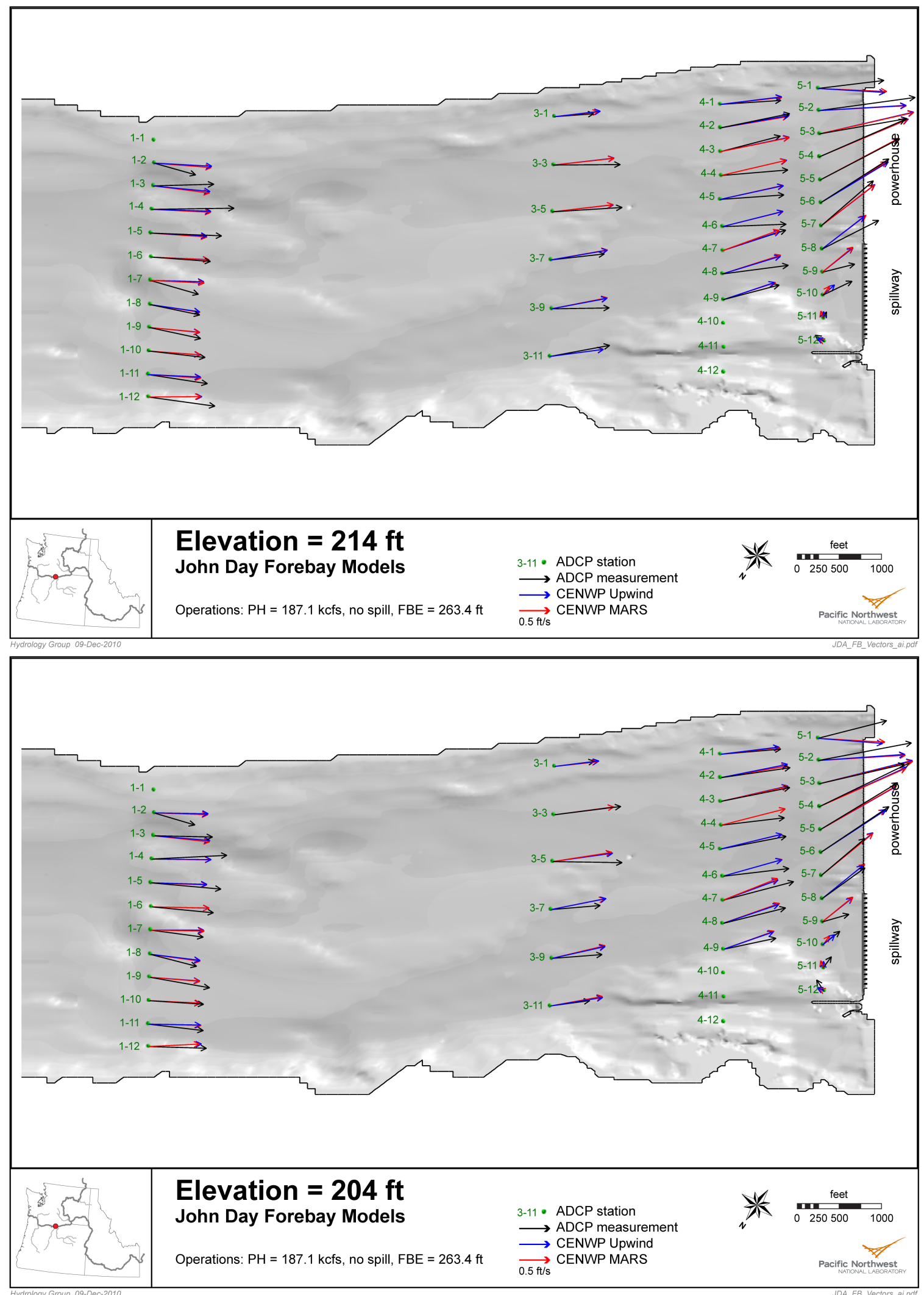

Figure 3.3. Comparison of Vectors from ADCP Measured Velocity, CENWP MARS Modeled Velocity, and the CENWP UD Model at an Elevation of $214 \mathrm{ft}$ (top) and $204 \mathrm{ft}$ (bottom) 


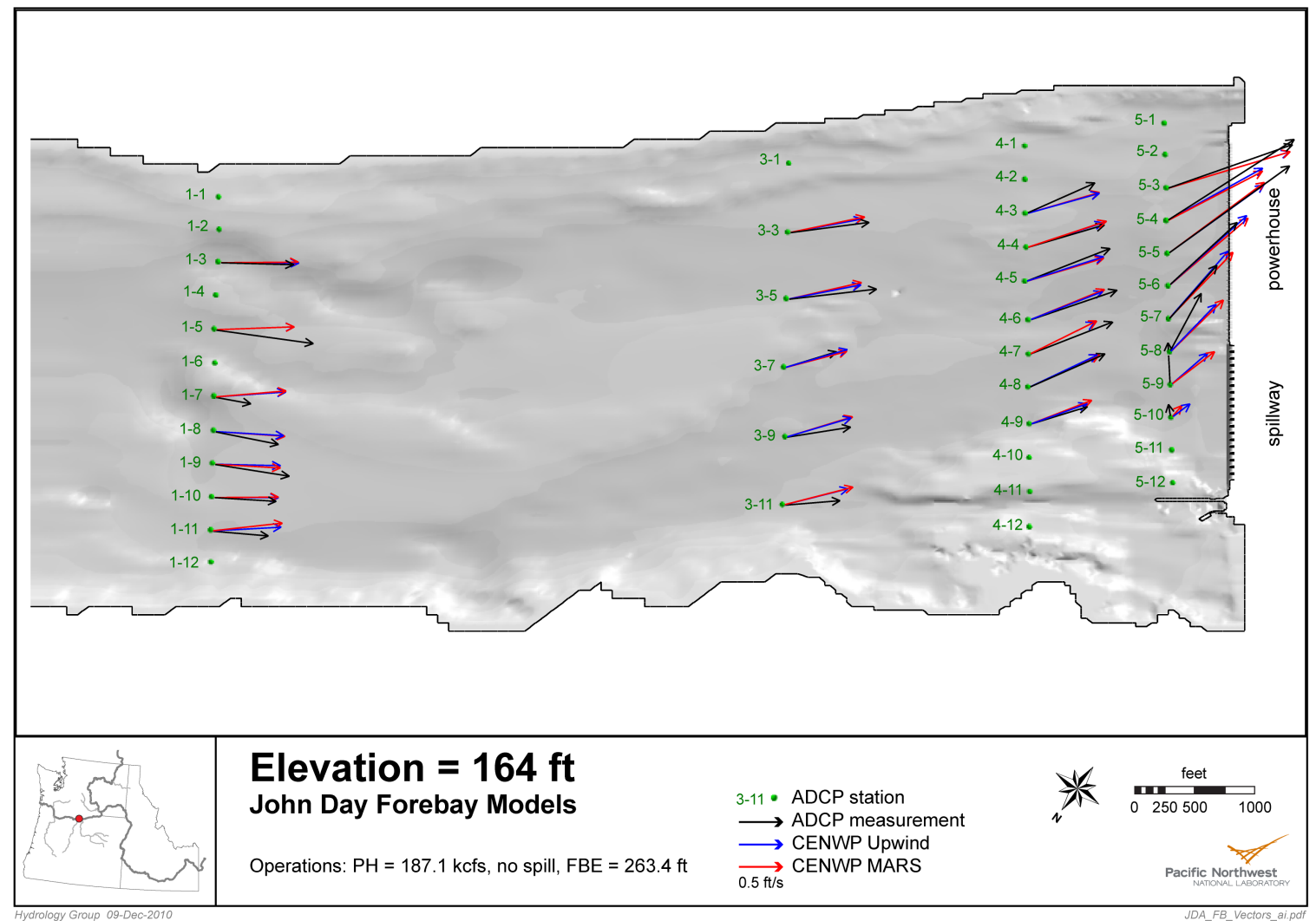

Figure 3.4. Comparison of Vectors from ADCP Measured Velocity, CENWP MARS modeled Velocity, and the CENWP UD Model at an Elevation of $164 \mathrm{ft}$ 


\section{Velocity Magnitude Comparison}

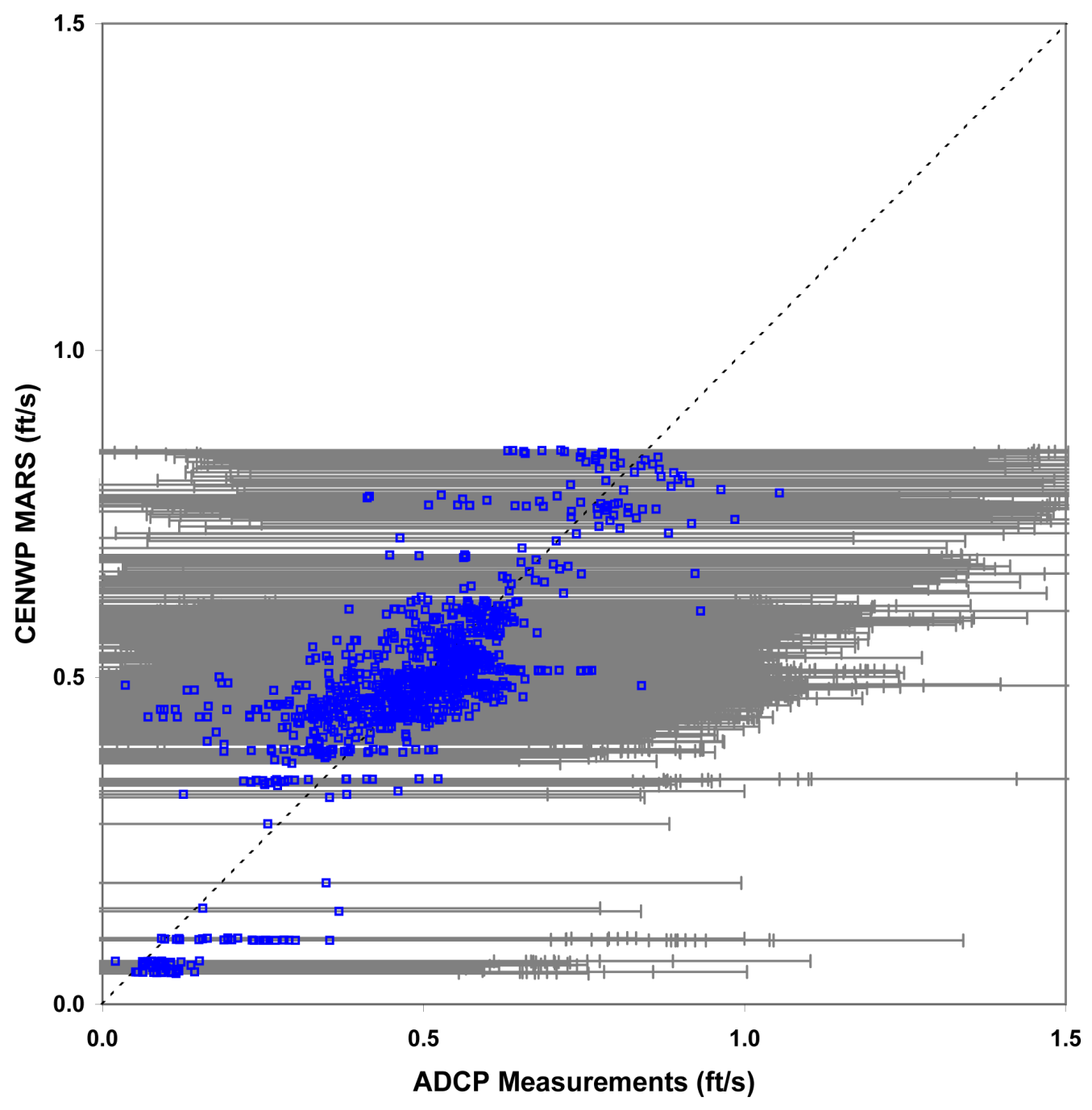

Figure 3.5. One to one comparison of ADCP-measured and CENWP MARS modeled velocity magnitude in the John Day forebay. The error bar for each point shows one standard deviation of the field measurements. Note that many of the standard deviations are larger than the measured velocity magnitude. 


\subsubsection{Model Refinement}

We tested if there were differences between the CENWP model and a refined version of that model (Figures 3.6 to 3.9). The CENWP model and refined model results were almost identical in the upstream portions of the model although they have different flow directions near the powerhouse. It should be noted that the unrefined model was more similar to the field-measured data for the velocity measurement points nearest the powerhouse.

Judgment needs to be used when applying these numerical models. A steady state model with a rigid lid will capture the overall flow patterns of the forebay, but is not intended to capture the transient nature of prototype flows. It does, however, capture the overall flow patterns and areas of recirculation. These comparisons are about the same as the validations results at the forebays of projects such as The Dalles Project and Bonneville Project. 

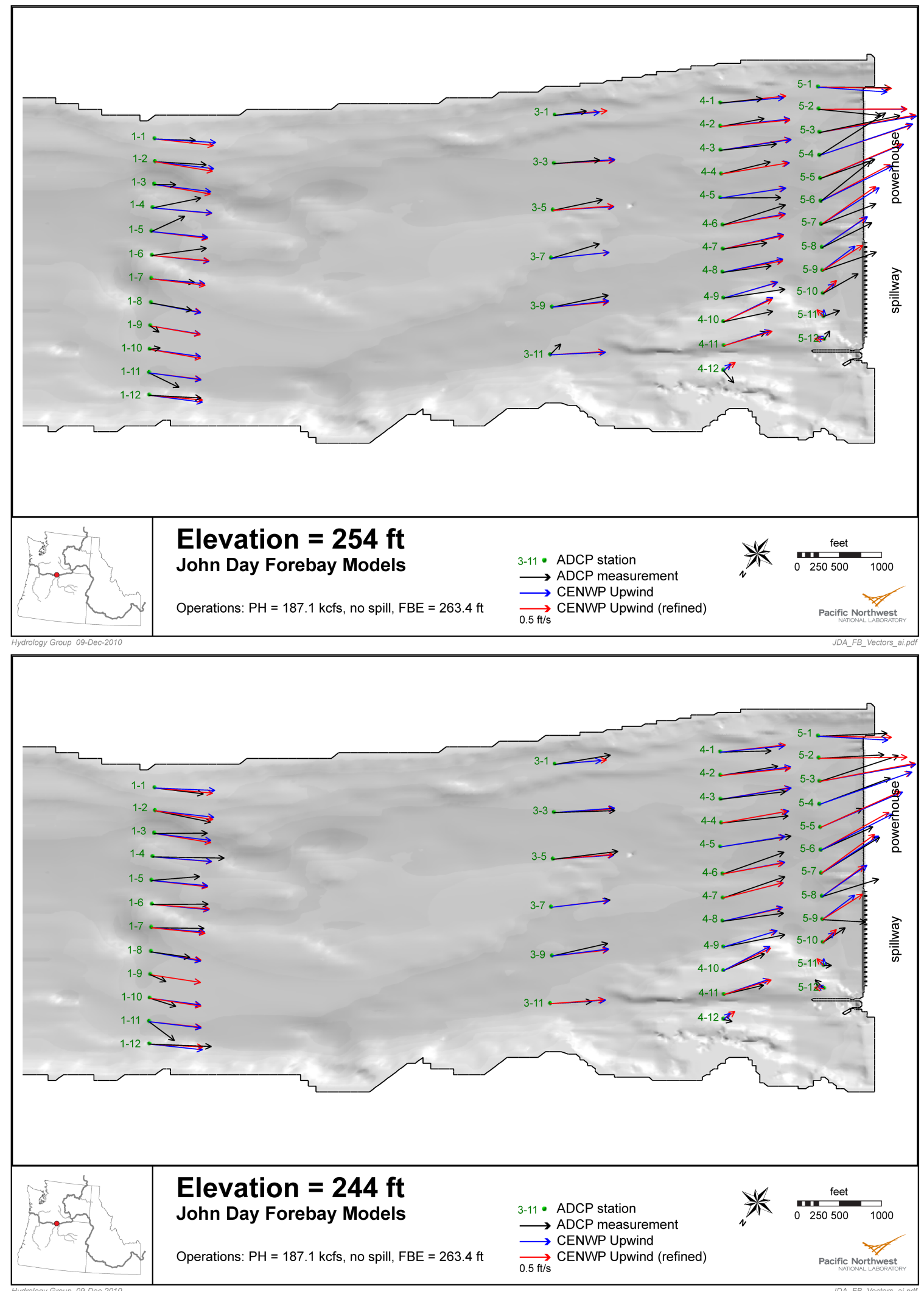

Figure 3.6. Comparison of Vectors from ADCP Measured Velocity, CENWP Modeled Velocity, and the CENWP Model as Refined by PNNL at an Elevation of $254 \mathrm{ft}$ (top) and 244 $\mathrm{ft}$ (bottom) 

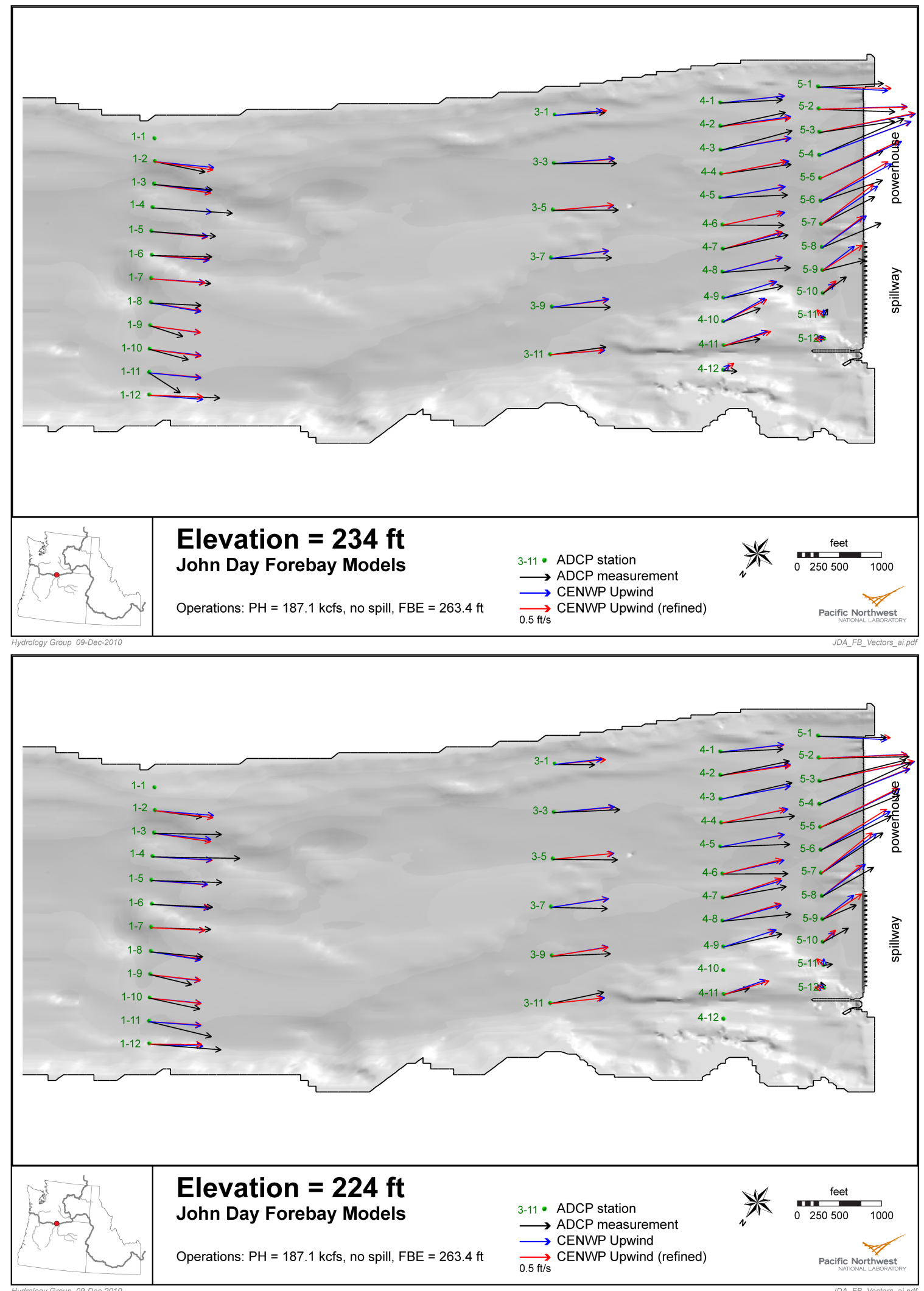

Figure 3.7. Comparison of Vectors from ADCP Measured Velocity, CENWP Modeled Velocity, and the CENWP Model as Refined by PNNL at an Elevation of $234 \mathrm{ft}$ (top) and 224 ft (bottom) 

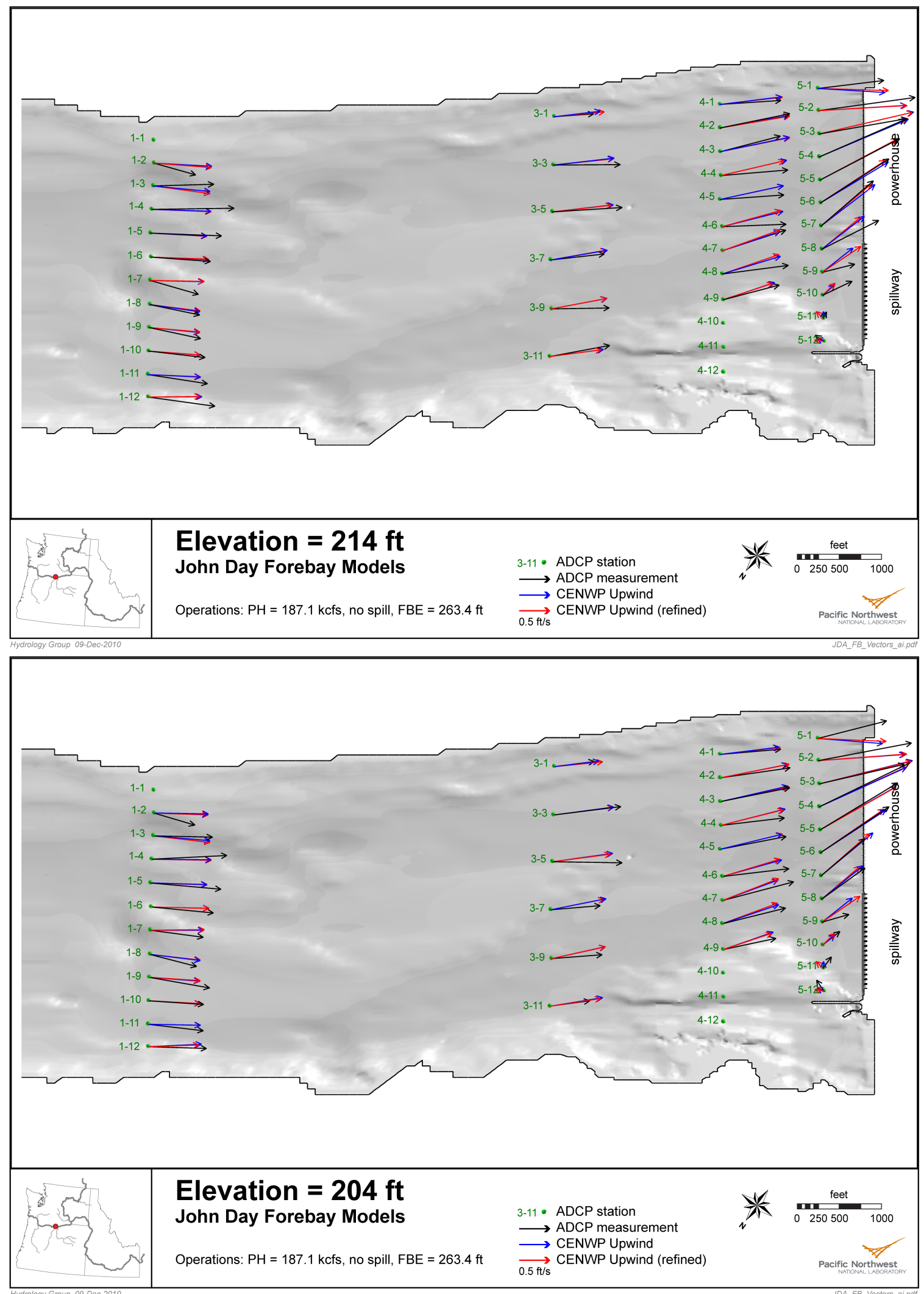

Figure 3.8. Comparison of Vectors from ADCP Measured Velocity, CENWP Modeled Velocity, and the CENWP Model as Refined by PNNL at an Elevation of $214 \mathrm{ft}$ (top) and 204 $\mathrm{ft}$ (bottom) 


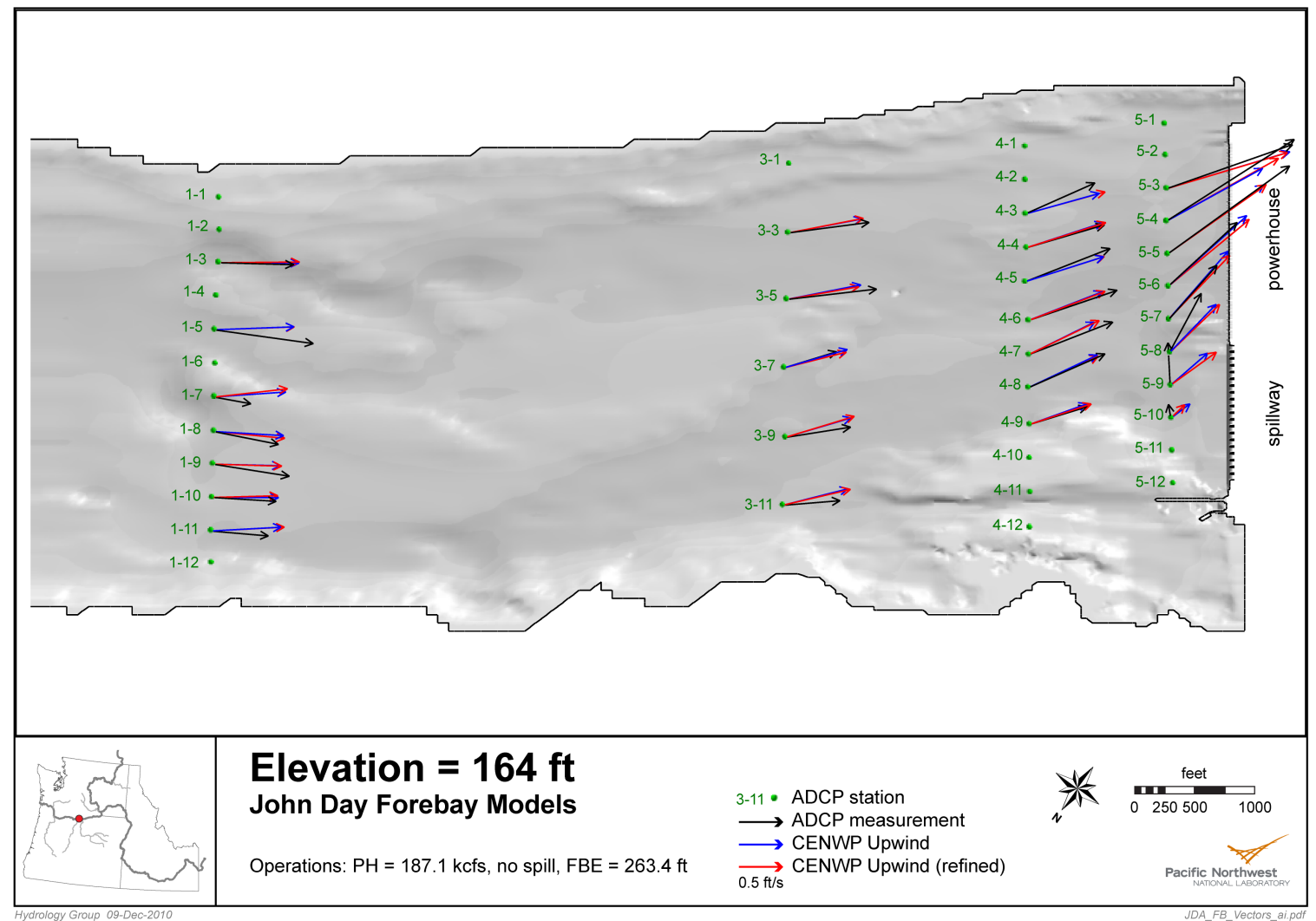

Figure 3.9. Comparison of Vectors from ADCP Measured Velocity, CENWP Modeled Velocity, and the CENWP Model as Refined by PNNL at an Elevation of $164 \mathrm{ft}$ 


\subsection{Conclusions and Recommendations}

The John Day forebay model developed by CENWP is adequately configured and validated. The model is appropriate for simulating forebay hydraulics for structural and operational alternatives. The approach and method are sound, however CENWP has identified some improvements that need to be made for future models and for modifications to this existing model. These include improving vertical resolution near the project (now a much easier task with software improvements), using the solver switch to improve the handling of cells of poor quality, and improving the processing of the underlying bathymetry to reduce the artifacts.

Recommendations include:

- Improve processing of bathymetric data to reduce processing artifacts,

- Use a staggered grid to create the regularly-spaced shell of triangles to be used for the bathymetric surface,

- Use a georeferenced coordinate system such as Oregon North, albeit truncated to reduce the number of significant digits,

- Use newer versions of STARCCM+ which have improved anisotropic meshing and allow much improved (and needed) vertical resolution near the water surface, and

- Use features of the newer CFD solver (either STAR-CD or STARCCM+) that improve the solver robustness and tolerance for ill-formed cells. 



\subsection{References}

Askelson S. 2009. Validation of the John Day Dam Forebay Star-CD Model. USACE-EC-HD, Portland, OR. Prepared for John Day Configuration and Alternatives Evaluation Study.

CD-adapco, Computational Dynamics Limited. 2006. CCM User Guide, STAR-CD Version 4.00. CD-adapco, http://www.cd-adapco.com.

CD-adapco, Computational Dynamics Limited. 2008. STAR-CCM+ User Guide version 3.0. CD-adapco, http://www.cd-adapco.com.

ENSR. 2001. Three-Dimensional Computational Fluid Dynamics Modeling of the Forebay of The Dalles Dam, Oregon. ENSR. DACW 3697-003-320.

Johnson G, M Hanks, F Khan, C Cook, J Hedgepeth, R Mueller, C Rakowski, M Richmond, S Sargeant, J Serkowski, and J Skalski. 2005a. Hydroacoustic Evaluation of Juvenile Salmonid Passage at The Dalles Dam in 2004. PNNL-15180, Pacific Northwest National Laboratory, Richland, Washington.

Johnson G, F Khan, J Hedgepeth, R Mueller, C Rakowski, M Richmond, J Serkowski, and J Skalski. 2005b. Hydroacoustic Evaluation of Juvenile Salmonid Passage at The Dalles Dam Sluiceway, 2005. PNNL-15540, Pacific Northwest National Laboratory, Richland, Washington.

Mannheim C and C Sweeney. 2003. Acoustic Doppler Current Profiler and Point Velocity Measurement Field Data Collection Lower Columbia River Projects. ENSR International. Final Report to the U.S. Army Corps of Engineers, Portland District, Oregon under Contract Number DACW57-02-D-0001.

Politano M, P Carrica, and L Weber. 2009. "A multiphase model for the hydrodynamics and total dissolved gas in tailraces." Journal of Multiphase Flow 35:1036-1050.

Rakowski C, L Ebner, and MC Richmond. 2005. "Juvenile Salmon Bypass and CFD Tools for Bonneville Dam on the Columbia River." Hydro Review 24(1).

Rakowski C, W Perkins, M Richmond, and J Serkowski. 2008. Simulation of The Dalles Dam Proposed Full Length Spillwall. PNNL-17322, Pacific Northwest National Laboratory. Memorandum for Record to the U.S. Army Corps of Engineers Portland, Oregon.

Rakowski C, M Richmond, and J Serkowski. 2006a. Forebay Computational Fluid Dynamics Modeling for The Dalles Dam to Support Vortex Suppression Device Studies. PNNL-16121, Pacific Northwest National Laboratory. Memorandum for Record to the U.S. Army Corps of Engineers Portland, Oregon.

Rakowski C, M Richmond, J Serkowski, and GE Johnson. 2006b. Forebay Computational Fluid Dynamics Modeling for The Dalles Dam to Support Behavior Guidance System Siting Studies. PNNL-15689, Pacific Northwest National Laboratory.

Rakowski C, J Serkowski, M Richmond, and K Recknagle. 2000. Development and Application of a 3D CFD Model for the Bonneville Project Powerhouse 1 and Powerhouse 2. Letter Report PNNL-13593, Pacific Northwest National Laboratory, Richland, Washington. Prepared for the U.S. Army Corps of Engineers, Portland District. 
Richmond M, C Rakowski, W Perkins, J Serkwoski, L Ebner, and S Schlenker. 2009. "Modeling Juvenile Salmon Egress Conditions in The Dalles Dam Tailrace using Computational Fluid Dynamics." In Waterpower 2009. Spokane, Washington.

Weber L, G.S.Constantinescu, M Haque, and M Koken. 2005. McNary Dam Forebay Temperature improvements computational fluid dynamics (CFD) numerical model study. IIHR.

WS Atkins Consultants and NSC. 2002. Best Practice Guidelines for Marine Applications of Computational Fluid Dynamics. https://pronet.wsatkins.co.uk/marnet/guidelines/guide.html. 



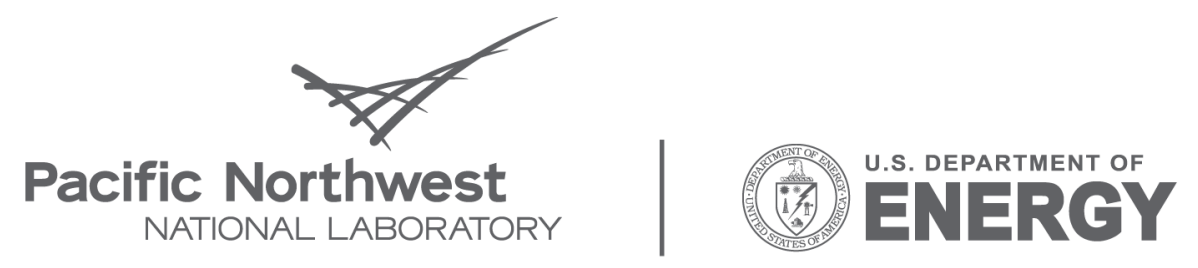

Proudly Operated by Battelle Since 1965

902 Battelle Boulevard

P.O. Box 999

Richland, WA 99352

1-888-375-PNNL (7665)

www.pnl.gov 